\title{
Effect of Aminophylline on Diaphragmatic Contractility in the Piglet
}

\author{
DENNIS E. MAYOCK, THOMAS A. STANDAERT, JON F. WATCHKO, AND \\ DAVID E. WOODRUM ${ }^{1}$ \\ University of Washington School of Medicine, Department of Pediatrics, Division of Neonatal and Respiratory \\ Diseases, Seattle, Washington 98195
}

\begin{abstract}
Minute ventilation, arterial blood gases, arterial pH, cardiac output, and transdiaphragmatic force generation, both during spontaneous ventilation and in response to phrenic nerve stimulation during airway occlusion at end expiration, were measured in nine anesthetized, tracheostomized piglets before and $\mathbf{3 0} \mathrm{min}$ after parenteral infusion of $20 \mathrm{mg} / \mathrm{kg}$ aminophylline. Serum theophylline levels averaged $109 \pm 21 \mu \mathrm{mol} / \mathrm{L}(19.7 \pm 3.7 \mu \mathrm{g} / \mathrm{mL})$ at $30 \mathrm{~min}$ postinfusion. No significant changes were noted in pH, blood gases, blood pressure, or ventilatory measures after aminophylline. Aminophylline infusion also had no effect on transdiaphragmatic force generation at any frequency of phrenic nerve stimulation studied. It is concluded that aminophylline has no effect on diaphragmatic contractility in the quietly breathing, nonfatigued piglet. (Pediatr Res 28: 196-198, 1990)
\end{abstract}

\section{Abbreviations}

Pdi, transdiaphragmatic pressure

Aminophylline has been shown to increase the force output of the diaphragm in adult human study subjects and animal models (1-13). This effect has been demonstrated for the nonfatigued (1-13) as well as the fatigued diaphragm $(1,6,10-12)$. The results of these studies have been extrapolated to the treatment of adult patients with respiratory failure (6). More recently, it has been suggested that methylxanthines may have a role in improving diaphragmatic force output in newborn infants $(14,15)$. However, data relevant to the effectiveness of methylxanthines in promoting improved force output in the newborn are sparse. Moreover, a clear understanding of the mechanism of action is lacking (16-18). We hypothesized that aminophylline would improve diaphragmatic contractility as evidenced by an increase in the force-frequency curve. This study was designed to assess the direct effect of aminophylline on contractility of the nonfatigued piglet diaphragm.

\section{MATERIALS AND METHODS}

Nine piglets were studied. Their mean postnatal age was $25 \pm$ $6 \mathrm{~d}$ and mean body wt, $4.58 \pm 1.72 \mathrm{~kg}$. Only healthy animals with a respiratory rate of $15-30$ breaths/min, a partial pressure

Received September 28, 1989; accepted April 13, 1990.

Correspondence: Dennis E. Mayock, M.D., Division of Neonatal and Respiratory Diseases, Department of Pediatrics, University of Washington, Seattle, WA 98195.

Supported in part by Pediatric Pulmonary Training Grant MCJ 000955 and HL 39187.

${ }^{1}$ Presented in part at the American Thoracic Society, Las Vegas, NV, May 811,1988 . of arterial oxygen $>8 \mathrm{kPa}$ (60 torr) in room air, and a partial pressure of the arterial carbon dioxide $\leq 6.7 \mathrm{kPa}$ (50 torr) were accepted for study. The animals were anesthetized with an i.v. combination of chloralose $(30 \mathrm{mg} / \mathrm{kg})$ and urethane $(150 \mathrm{mg} /$ $\mathrm{kg}$ ) and studied in the supine position. Subsequent infusions of anesthetic were used if the piglet developed jaw clonus. A tracheostomy was placed and connected to a two-way nonrebreathing valve (model 2384, Hans Rudolph, Inc., Kansas City, MO). Inspiratory flow was detected by a hot-wire anemometer and integrated to provide tidal volume. All animals breathed $50 \%$ oxygen-balance nitrogen throughout the study. A femoral artery catheter was placed to measure heart rate and blood pressure, and to obtain samples for blood gas and $\mathrm{pH}$ analysis. Rectal temperature was continuously monitored and maintained at 39 $\pm 0.5^{\circ} \mathrm{C}$ by a radiant warmer.

Force-frequency curves were generated by the transvenous phrenic nerve stimulation technique as previously described (19, 20). The phrenic nerves were stimulated via bilateral indwelling external jugular vein catheter electrodes with supramaximal voltage at $20,30,50$, and $100 \mathrm{~Hz}$. Transdiaphragmatic force generation (Pdi) during airway occlusion at end expiration was measured as gastric pressure (Pgas) minus proximal airway pressure (Paw): Pdi = Pgas - Paw (21-23). Proximal airway pressure was measured by a P10EZ (Spectramed, Inc., Oxnard, CA) pressure transducer connected to an 18-gauge needle inserted in the tracheostomy tube between the animal and the nonrebreathing valve. A thin-walled latex balloon containing $0.5 \mathrm{~mL}$ of air was connected to a polyethylene catheter (1.65-mm inner diameter) and placed in the stomach to measure gastric pressure with a similar transducer.

A preformed plaster cast covering the entire abdomen and lower third of the chest was applied during force-frequency curve generation to ensure a constant degree of diaphragmatic shortening. The piglets were allowed to breathe unrestricted between stimuli. Chest wall distortion, if present, was assessed by respiratory inductive plethysmography (Respitrace, Ambulatory Monitoring, Inc., Ardsley, NY). Distortion was quantified in arbitrary units. A Swan-Ganz thermal dilution catheter ( 5 French with 10-cm proximal port, American Edwards Laboratories, Irvine, CA) was placed in the pulmonary artery under fluoroscopic guidance to measure cardiac output. Measures of cardiac output were obtained in triplicate using $2 \mathrm{~mL}$ iced $5 \%$ dextrose in water. End-expiratory lung volume was measured in three animals during baseline and again at 30 min post aminophylline infusion using the nitrogen washout technique (24).

Experimental protocol. After a 30 -min stabilization period, baseline data were collected including arterial blood gases and $\mathrm{pH}$, ventilatory parameters (tidal volume, respiratory rate, minute ventilation), cardiac output, systemic blood pressure, heart rate, chest wall distortion, and end-expiratory lung volume $(n=$ 3 ), and a force-frequency curve was generated. Aminophylline was then infused $(20 \mathrm{mg} / \mathrm{kg})$ over $10 \mathrm{~min}$. Data including serum 
theophylline levels were again collected at $30 \mathrm{~min}$ after the theophylline infusion.

All values are given as the mean \pm SD unless indicated. Statistical comparisons were made using analysis of variance and the paired $t$ test.

\section{RESULTS}

Data from the baseline and the 30-min study period are given in Table 1. No differences were noted in any ventilatory or hemodynamic measure from baseline to $30 \mathrm{~min}$. Spontaneously generated Pdi was not affected by aminophylline $(5.5 \pm 1.6$ $\mathrm{cmH}_{2} \mathrm{O}$ at baseline versus $5.4 \pm 2.0 \mathrm{~cm} \mathrm{H}_{2} \mathrm{O} 30$ min post aminophylline infusion). Chest wall distortion during force-frequency curve generation at $30 \mathrm{~min}$ post theophylline infusion was not different from baseline at any frequency of phrenic nerve stimulation (Table 2). The results of force-frequency curve generation are shown in Fig. 1. No change was noted between baseline and $30 \mathrm{~min}$ post aminophylline infusion. End-expiratory lung volume did not change from baseline to $30 \mathrm{~min}$ postinfusion ( $18 \pm 2$ versus $17 \pm 1 \mathrm{~mL} / \mathrm{kg}, n=3$ ). Serum theophylline levels averaged $109 \pm 21 \mu \mathrm{mol} / \mathrm{L}(19.7 \pm 3.7 \mu \mathrm{g} / \mathrm{mL})$.

\section{DISCUSSION}

The data generated by our study demonstrate that aminophylline has no effect on diaphragmatic contractility in the spontaneously breathing, nonfatigued, anesthetized piglet. Thus, the hypothesis of the study was rejected. To accept these results, the accuracy of the techniques used to determine force-generating capability of the diaphragm must first be assessed.

Critique. Our study was designed to focus on the diaphragm. Therefore, it was necessary to control central respiratory drive to the diaphragm and exclude the possibility of altered CNS output $(25,26)$. Accordingly, bilateral phrenic nerve stimulation was used to assess diaphragmatic function as previously described $(19,20,27)$. The transdiaphragmatic pressure generated during phrenic nerve stimulation at end-expiratory lung volume was used as a measure of force-generating capacity.

Previous work in our laboratory has demonstrated that proximal airway pressure is superior to esophageal pressure as an estimate of intrapleural pressure during phrenic nerve stimulation (21-23). Accordingly, the measurement of transdiaphragmatic pressure in this model used proximal airway rather than esophageal pressure as an estimate of intrapleural pressure.

The force generated by the diaphragm for a given level of phrenic nerve input is a function of its length and geometry (28). Both of these factors are dependent on chest wall configuration and lung volume. Changes in chest wall configuration were minimized by the application of a snug-fitting plaster cast to the entire abdomen and lower third of the rib cage during Pdi measurement at end-expiratory lung volume. This was confirmed by lack of change in chest wall distortion as assessed by respiratory inductive plethysmography. Additionally, data generated as a subset of study animals suggest that end-expiratory lung volume did not change after aminophylline. Therefore, the length and geometry of the diaphragm were assumed not to be altered by aminophylline.

Methylxanthine effect on diaphragm. The methylxanthines are thought to affect muscle function by altering calcium ion flux across the cell membrane, including the sarcoplasmic reticulum and the T-tubular system $(2,16,29,30)$. Theophylline also causes hyperpolarization of the resting membrane potential, whereas caffeine has no effect (31). Both drugs raise intracellular $\mathrm{pH}(32)$, which affects calcium ion reuptake (33).

The reason for the lack of effect of aminophylline on diaphragmatic contractility in our study is not clear. The blood levels of theophylline achieved may not have been adequate to result in improved diaphragmatic contractility in the piglet. Because this study was designed to evaluate diaphragmatic function in a manner that could be extrapolated to the human neonate, the dosage of aminophylline used was calculated to result in serum levels at the high end of the acceptable clinical range (34). Indeed, Singrist et al. (8) demonstrated that aminophylline increased diaphragmatic contractility in a dose-related manner in the anesthetized adult dog. However, the peak effect was found at 80 $\mathrm{mg} / \mathrm{kg}$, a dosage 4 times greater than clinically therapeutic in adult humans. An alternative explanation may relate to subcellular structural differences. For example, the sarcoplasmic reticulum and the T-tubular system are incompletely developed in the newborn (35). Thus, cellular components thought to be key in the excitation-contraction phase may be unable to respond to the proposed drug effect on calcium flux phenomena.

Comparison to studies in adults. Our data are in conflict with investigations that demonstrated beneficial effects of methylxanthine drugs on diaphragmatic contractility in adult humans and animals. Aubier et al. (1) and Supinski et al. (9) both demonstrated a beneficial effect of methylxanthine drugs on diaphragmatic force output in adult humans. Sigrist et al. (8) demonstrated that aminophylline increased diaphragmatic contractility in a dose-dependent fashion in nonfatigued adult dogs. Similar findings have been demonstrated during metabolic acidosis (5) and hypercapnia (4) and in fresh and fatigued diaphragm in adult hamsters (12), adult rat diaphragms (36), adult human patients with chronic obstructive pulmonary disease (6), adult guinea pigs (13), and adult dogs (3). The beneficial effect of methylxanthine drugs on diaphragmatic contractility was apparent despite the use of anesthesia in some of the studies $(2-5,8)$. All these studies concluded that methylxanthine drugs would be of benefit in patients with diaphragmatic failure or fatigue.

Other investigators have not found improvement in diaphragmatic muscle force generation after methylxanthine drug administration. Paton et al. (37) found no improvement in ventilatory muscle strength or endurance in normal adult humans. In normal volunteers and in patients with chronic obstructive pulmonary disease, Belman et al. (38) could only demonstrate small improvements in ventilatory endurance thought to be of little significance. Foxworth et al. (17) and Kongragunta et al. (39) also found no improvement in diaphragmatic force generation in patients with severe chronic obstructive pulmonary disease. These studies all questioned the efficacy of methylxanthine drugs used to improve diaphragmatic function.

More recent investigations suggest that methylxanthines may result in adverse effects on diaphragmatic function. Miller and Reid (40) found that theophylline did not delay the onset of fatigue in the rat diaphragm and, indeed, inhibited force recovery after fatigue. Haack et al. (41) demonstrated that theophylline accelerated fatigue of isolated rat diaphragm muscle strips. Theophylline enhanced fatigue in hamster diaphragm $(42,43)$ in addition to slowing relaxation in the fatigued state (16). Thus,

Table 1. Effect of aminophylline on cardiopulmonary measurements*

\begin{tabular}{lccrrrrrr} 
& $\mathrm{HR}$ & $\mathrm{CO}$ & \multicolumn{1}{c}{$\mathrm{BP}$} & \multicolumn{1}{c}{$\mathrm{Vt}$} & $\dot{\mathrm{Ve}}$ & \multicolumn{1}{c}{$\mathrm{PaO}_{2}$} & $\mathrm{PaCO}_{2}$ & Theophylline level \\
\hline Preamino & $175 \pm 38$ & $216 \pm 40$ & $96 \pm 6$ & $9.0 \pm 1.9$ & $182 \pm 37$ & $191 \pm 29$ & $43 \pm 4$ & \\
Postamino & $196 \pm 67$ & $211 \pm 36$ & $101 \pm 9$ & $10.2 \pm 2.2$ & $207 \pm 85$ & $175 \pm 41$ & $47 \pm 6$ & $109 \pm 21(19.7 \pm 3.7)$ \\
\hline
\end{tabular}

* Preamino, baseline values before aminophylline infusion; Postamino, values $30 \mathrm{~min}$ postaminophylline infusion; HR, heart rate in beats/min; $\mathrm{CO}$, cardiac output in $\mathrm{mL} / \mathrm{kg} / \mathrm{min} ; \mathrm{BP}$, mean blood pressure in $\mathrm{mm} \mathrm{Hg} ; \mathrm{Vt}$, tidal volume in $\mathrm{mL} / \mathrm{kg} ; \dot{\mathrm{Ve}}$, minute ventilation in $\mathrm{mL} / \mathrm{kg} / \mathrm{min} ; \mathrm{PaO}{ }_{2}$, partial pressure of arterial oxygen in torr; $\mathrm{PaCO}_{2}$, partial pressure of arterial carbon dioxide in torr. Serum theophylline levels in $\mu \mathrm{mol} / \mathrm{L}(\mu \mathrm{g} / \mathrm{mL})$. All values are mean $\pm \mathrm{SD}$. No significant differences were noted between baseline and postinfusion measures. 
Table 2. Chest wall distortion*

\begin{tabular}{llllc}
\hline & $20 \mathrm{~Hz}$ & $30 \mathrm{~Hz}$ & $50 \mathrm{~Hz}$ & $100 \mathrm{~Hz}$ \\
\hline Preamino & $4 \pm 2$ & $4 \pm 3$ & $5 \pm 3$ & $5 \pm 3$ \\
Postamino & $4 \pm 2$ & $5 \pm 3$ & $5 \pm 4$ & $6 \pm 5$ \\
\hline
\end{tabular}

* Chest wall distortion in arbitrary units as obtained by inductive plethysmography. $\mathrm{Hz}$, frequency of phrenic nerve stimulation during force frequency curve generation. Mean $\pm \mathrm{SD}$.

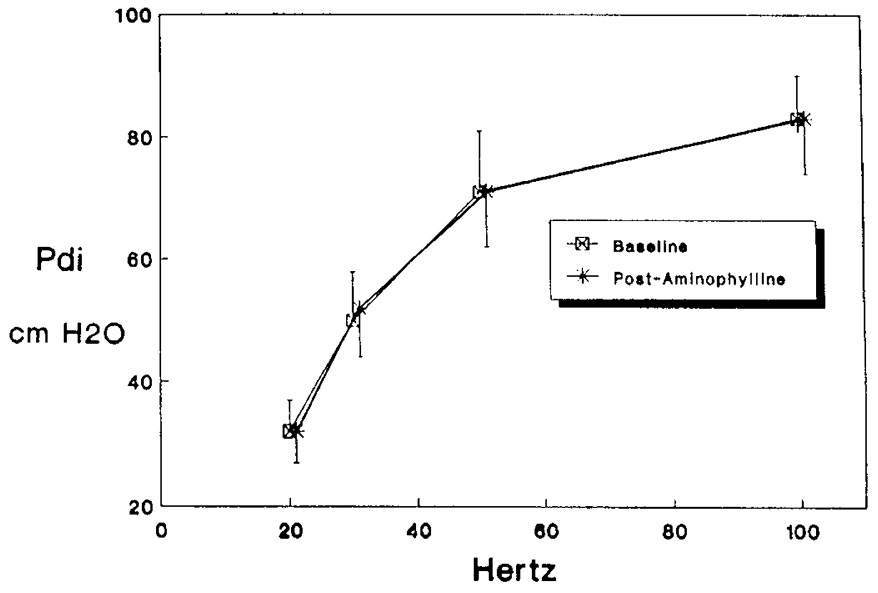

Fig. 1. No change in the force-frequency curve was noted from baseline (thin line) to 30 min post aminophylline infusion (thick line). Values are mean \pm SEM. Values at 30 min post aminophylline are slightly offset for clarity. Hertz, frequency of phrenic nerve stimulation. Pdi, given in $\mathrm{cm}$ of water.

there are data suggesting that methylxanthines may adversely affect diaphragmatic force output. Whether methylxanthine drugs would result in improved diaphragmatic contractility in the absence of anesthesia cannot be answered by our study. Based on the above information, it would seem that a clear idea as to the efficacy of methylxanthines to augment diaphragmatic contractility during weaning from mechanical ventilatory support is lacking, and most certainly there are few data to support their use in the neonate.

\section{REFERENCES}

1. Aubier M, De Troyer A, Sampson M, Macklem PT, Roussos CH 1981 Aminophylline improves diaphragmatic contractility. $N$ Engl J Med 305:249-252

2. Aubier M, Murciano D, Viires N, Lecocguic Y, Pariente R 1983 Diaphragmatic contractility enhanced by aminophylline: role of extracellular calcium. J Appl Physiol 54:460-464

3. Aubier M, Murciano D, Viires N, Lecocguic Y, Palacios S, Pariente R 1983 Increased ventilation caused by improved diaphragmatic efficiency during aminophylline infusion. Am Rev Respir Dis 127:148-154

4. Howell S, Fitzgerald RS, Roussos CH 1985 Effects of aminophylline, isoproterenol, and neostigmine on hypercapnic depression of diaphragmatic contractility. Am Rev Respir Dis 132:241-247

5. Howell S, Fitzgerald RS, Roussos CH 1986 Effects of aminophylline and salbutamol on diaphragmatic force during compensated metabolic acidosis. Am Rev Respir Dis 133:407-413

6. Murciano D, Aubier M, Lecocguic Y, Pariente R 1984 Effects of theophylline on diaphragmatic strength and fatigue in patients with chronic obstructive pulmonary disease. N Engl J Med 311:349-353

7. Murciano D, Aubier M, Viires N, Mal H, Pariente R 1987 Effects of theophylline and enprofylline on diaphragmatic contractility. J Appl Physiol 63:5157

8. Sigrist S, Thomas D, Howell S, Roussos CH 1982 The effect of aminophylline on inspiratory muscle contractility. Am Rev Respir Dis 126:46-50

9. Supinski GS, Deal EC, Kelsen SG 1984 The effects of caffeine and theophylline on diaphragm contractility. Am Rev Respir Dis 130:429-433

10. Supinski GS, Levin S, Kelsen SG 1986 Caffeine effect on respiratory muscle endurance and sense of effort during loaded breathing. J Appl Physiol 60:2040-2047
11. Viires N, Aubier M, Murciano D, Fleury B, Talamo C, Pariente R 1984 Effects of aminophylline on diaphragmatic fatigue during acute respiratory failure. Am Rev Respir Dis 129:396-402

12. Wittmann TA, Kelsen SG 1982 The effect of caffeine of diaphragmatic muscle force in normal hamsters. Am Rev Respir Dis 126:499-504

13. Zavecz JH 1984 Fatigue of the guinea-pig diaphragm in vitro: effect of terbutaline and caffeine. Res Commun Subst Abuse 5:303-312

14. Lopes JM, LeSouef PN, Bryan H, Bryan AC 1982 The effects of theophylline on diaphragmatic fatigue in the newborn. Pediatr Res 16:355A(abstr)

15. McGilliard KL, Farrell LC 1988 Effects of xanthine and adenoside analogs on contractility of the newborn rat diaphragm. Physiologist 31:A7(abstr)

16. Esau SA 1988 Slowing of relaxation in the fatiguing hamster diaphragm is enhanced by theophylline. J Appl Physiol 65:1307-1313

17. Foxworth JW, Reisz GR, Knudson SM, Cuddy PG, Pyszczynski DR, Emory CE 1988 Theophylline and diaphragmatic contractility. Am Rev Respir Dis 138:1532-1534

18. Viires N, Aubier M, Murciano D, Marty C, Pariente R 1986 Effects of theophylline on isolated diaphragmatic fibers. Am Rev Respir Dis 133:1060 1064

19. Mayock DE, Badura RJ, Watchko JF, Standaert TA, Woodrum DE 1987 Response to resistive loading in the newborn piglet. Pediatr Res 21:121-125

20. Watchko JF, Mayock DE, Standaert TA, Woodrum DE 1986 Diaphragmatic pressures in piglets: direct versus transvenous phrenic nerve stimulation. Pediatr Pulmonol 2:198-201

21. Mayock DE, Standaert TA, Woodrum DE 1989 Effects of digoxin on diaphragmatic contractility in the piglet. Pediatr Res 25:271-273

22. Mayock DE, Standaert TA, Woodrum DE 1989 Airway occlusion versus intrapleural pressure during phrenic nerve stimulation in the piglet. Clin Res 37:213A(abstr)

23. Mayock DE, Watchko JF, Standaert TA, Woodrum DE 1990 Estimation of intrapleural pressure in the newborn. Pediatr Pulmonol (in press)

24. Standaert TA, LaFramboise WA, Tuck RE, Woodrum DE 1985 The serial determination of lung volume in small animals by nitrogen washout. J Appl Physiol 59:205-210

25. Bigland-Ritchie B, Jones DA, Hosking GP, Edwards RHT 1978 Central and peripheral fatigue in sustained maximum voluntary contractions of human quadriceps muscle. Clin Sci Mol Med 54:609-614

26. Bigland-Ritchie B, Johansson R, Lippold OCJ, Smith S, Woods JJ 1983 Changes in motoneurone firing rates during sustained maximal voluntary contractions. J Physiol (Lond) 340:335-346

27. Planas RF, McBrayer RH, Koen PA 1985 Diaphragmatic pressures: transvenous $v s$. direct phrenic nerve stimulation. J Appl Physiol 59:269-273.

28. Grassino A, Goldman MD, Mead J, Sears TA 1978 Mechanics of the human diaphragm during voluntary contraction: statics. J Appl Physiol 44:829-839

29. Varagic VM, Kentera D 1978 Interactions of calcium, dibutyryl cyclic AMP, isoprenaline and aminophylline on the isometric contraction of the isolated hemidiaphragm of the rat. Naunyn Schmiedebergs Arch Pharmacol 303:47 53

30. Weber A 1968 The mechanism of the action of caffeine on sarcoplasmic reticulum. J Gen Physiol 52:760-772

31. Fink R, Lattgau HC 1976 An evaluation of the membrane constants and the potassium conductance in metabolically exhausted muscles fibers. J Physiol (Lond) 263:215-238

32. Connett $\mathrm{RJ} 1978$ Association of increased $\mathrm{pH}_{\mathrm{i}}$ with calcium ion release in skeletal muscle. Am J Physiol 234:C110-C114

33. Edwards RHT, Hill DK, Jones DA 1975 Metabolic changes associated with the slowing of relaxation of fatigued mouse muscle. J Physiol (Lond) 251:287-301

34. Davi M, Rigatto H 1985 Apnea. In: Nelson NM (ed) Current Therapy in Neonatal-Perinatal Medicine. CV Mosby Co, St. Louis, pp 147-149

35. Maxwell LC, McCarter RJM, Kuehl TJ, Robotham JL 1983 Development of histochemical and functional properties of baboon respiratory muscles. J Appl Physiol 54:551-561

36. Kramer GL, Wells JN 1980 Xanthines and skeletal muscle: lack of relationship between phosphodiesterase inhibition and increased twitch tension in rat diaphragms. Mol Pharmacol 17:73-78

37. Paton JY, Swaminathan S, Ward SLD, Sargent CW, Keens TG 1989 Theophylline does not improve ventilatory muscle strength and endurance in normal adults. Am Rev Respir Dis 139:166A(abstr)

38. Belman MJ, Sieck GC, Mazar A 1985 Aminophylline and its influence on ventilatory endurance in humans. Am Rev Respir Dis 131:226-229

39. Kongragunta VR, Druz WS, Sharp JT 1988 Dyspnea and diaphragmatic fatigue in patients with chronic obstructive pulmonary disease. Am Rev Respir Dis 137:662-667

40. Miller MJ, Reid MB 1988 Theophylline does not delay diaphragm fatigue or improve recovery. Am Rev Respir Dis 137:70A(abstr)

41. Haack KE, Londono B, Miller MJ, Reid MB 1988 Theophylline accelerates fatigue and changes force-frequency curve of rat diaphragm in a time- and dose-dependent manner. Physiologist 31:A223(abstr)

42. Esau SA 1988 Theophylline increases the slowing of relaxation in contracting hamster diaphragm muscle. Am Rev Respir Dis 137:385A(abstr)

43. Esau SA 1989 Theophylline enhances fatigue in hamster diaphragm muscle studied in an hypoxic, hypercapnic environment. Am Rev Respir Dis 139:162A(abstr) 